\title{
“MÚSICA DE FEITIÇARIA NO BRASIL: CONFERÊNCIA LITERÁRIA"
}

Juliana Araújo Silva*

RESUMO:

Este ensaio trata do modo como Mário de Andrade articula ciência e literatura em seu texto "Música de feitiçaria no Brasil: conferência literária", conforme procedimentos de composição identificados e estudados por ele na cultura popular brasileira.

PALAVRAS-CHAVE: Mário de Andrade, Brasil, folclore, literatura.

para Mateus, para Toya

0 aproveitamento da cultura popular na criação erudita de Mário de Andrade, que marcará toda a sua obra literária, se faz perceber já em alguns de seus primeiros contos ou em seu primeiro livro de poemas modernistas, Paulicéia Desvairada, como, mais tarde, em Clã do Jaboti ou Macunaíma. Assim também os diários que o autor escreve durante as viagens ao Norte, em 1927, e ao Nordeste, em 1928, deveriam se transformar em uma narrativa de viagens, sob o título de 0 Turista Aprendiz.

Mário não chega a publicar o livro, mas os dois diários serão utilizados, ao longo dos anos, na composição de outras obras. Telê Porto Ancona Lopez examina o reaproveitamento dos textos do planejado Turista Aprendiz em Macunaíma, assim como em muitos dos poemas do autor. 0 livro de crônicas Os Filhos da Candinha, de 1943, conta com cinco dos textos do segundo diário, publicados em primeira mão no Diârio Nacional na série "crônicas diárias".

| Mestre em Letras: Estudos Literários (Área de concentração: Literatura Brasileira), 2003. 


\section{EMTESE}

Belo Horizonte, v. 8, p. I-243, dez. 2004

Além de usar a cultura popular em sua literatura, Mário, por volta de 1930, demonstra interesse pela abordagem científica da matéria. Ele alentara a idéia de produzir, a partir do material que colhera em suas viagens ao Norte e ao Nordeste, uma obra que representasse contribuição aos estudos sobre a cultura popular brasileira. 0 autor começa, então, a estudar sistematicamente o assunto, a fim de fundamentar suas análises, e passa a escrever artigos, ensaios e conferências sobre suas pesquisas.

Os volumes Danças Dramáticas do Brasil reúnem alguns desses artigos, nos quais Mário discute os processos da cultura popular brasileira, comparando dados históricos, pesquisas de outros estudiosos, bem como os dados de sua própria coleta. Esses procedimentos estão presentes também na conferência que abre o seu volume Música de Feitiçaria no Brasil. No entanto, Mário inseriu na conferência, praticamente na íntegra, a crônica do diário da viagem ao Nordeste "Natal, 28 de dezembro, 24 horas", publicada entre as "crônicas diárias" da série "0 Turista Aprendiz" no Diário Nacional, em que ele conta como aconteceu a cerimônia de fechamento de seu corpo, num Catimbó em Natal. A presença de tal crônica no texto da conferência constitui uma significativa diferença entre essa última e os artigos mencionados.

As "crônicas diárias" da série "0 Turista Aprendiz", publicadas no Diário Nacional entre dezembro de 1928 e março de 1929, como já foi dito, são escritas sob a forma de um diário de viagem, durante o período em que o autor esteve no Nordeste do país, esforçando-se por registrar e revelar aos seus leitores aspectos de um Brasil ainda pouco conhecido. Telê Porto Ancona Lopez identifica nelas elementos de "referencialidade pura" (Jakobson), na apresentação de resultados da "pesquisa etnográfica" empreendida pelo turista aprendiz: "comunicações", "notas" e "informações". Mas ela observa que Mário "foge à objetividade de um correspondente, deixando também seu estado de espírito na hora em que está escrevendo e a revisão da jornada à luz dos sentimentos. Não é mais a hora do fato, mas a hora do autor." Em outro texto, Telê expõe a proposta de gênero indicada por Mário para o conjunto das crônicas de 0 Turista Aprendiz: narrativa de viagens, concebida por ele sob duas acepções: 
"Teremos a narrativa do cronista, presa à referencialidade (Jakobson), à fixação do real e do verídico, mas elástica a ponto de permitir que a subjetividade possa dissolver o dado na impressão, ou valorizá-1o no discurso poético. A seu lado, teremos a narrativa do ficcionista que manipula artisticamente tempo e espaço, cria personagens, estabelece pontos de vista no narrar, experimenta estilos, sabe criar suspense e explorar tensões. Por vezes, desenvolvendo o episódio vivido, ou o caso escutado, transforma-o num verdadeiro conto que poderá ser lido fora de seu contexto de origem. (...) Mário, modernista e também nacionalista, fará ficção a partir da própria realidade experimentada ou observada, fazendo questão de explorá-la em dois aspectos: o real, e o ficcional, partindo desse mesmo real."

De fato, na crônica "Natal, 28 de dezembro, 24 horas", percebe-se 0 "estado de espírito" do autor, de que fala Telê. Há aí uma considerável recorrência de expressões que iluminam não o objeto que se observa, mas a subjetividade do autor. Além disso, o juízo do autor e suas reações emotivas apresentados na crônica são reforçados pelo ritmo das frases, ou pelo acúmulo de adjetivos. Juntam-se a isso as onomatopéias, a utilização, irônica, das falas dos catimboseiros em discurso direto: tudo se organizando de modo a recriar a materialidade da cerimônia. Os aspectos formais do texto ganham relevo, o acontecido transforma-se numa história, os mestres catimboseiros em personagens, e o autor da conferência se transforma em narrador. A predominância da função poética na crônica confere a ela um caráter literário e a sua presença no interior da conferência faz dessa última um texto de natureza bem peculiar.

Ora, nos estudos incluídos em Danças Dramáticas do Brasil, Mário utiliza, de suas anotações de viagem, apenas os aspectos documentais do que observara. As descrições de bailados que figuram nesses estudos são essencialmente objetivas, não se detendo nem sobre os sentimentos nem sobre o juízo do autor. Não se percebe neles a intenção artística.

A conferência sobre a música de feitiçaria no Brasil foi escrita para a Associação Brasileira de Música e lida pela primeira vez na Escola Nacional de Música do Rio de Janeiro, em 1933, e posteriormente no Conservatório Dramático e Musical de São Paulo, em data desconhecida. Em 1944, Mário reflete sobre seu gênero. Conforme explicação de Oneyda Alvarenga, neste ano, antes de submeter-se a uma operação, ele deixava em carta autorização para que sua conferência "Música de Feitiçaria no Brasil" fosse publicada tal como se encontravam os originais, devendo, 


\section{EMTESE}

Belo Horizonte, v. 8, p. I-243, dez. 2004

no entanto, ser acrescentado o subtítulo "conferência literária", pois havia planejado um trabalho definitivo "muito mais sério e científico".

Se admitirmos a divisão dos textos de Mário originados do material etnográfico colhido em suas viagens ao Norte e ao Nordeste em dois grupos de natureza distinta - o dos estudos dissertativos sobre a cultura popular, como alguns dos artigos publicados em Danças Dramáticas do Brasil, e o das obras de caráter literário, como a narrativa de viagens 0 Turista Aprendiz, de que fariam parte as "crônicas diárias" publicadas no Diário Nacional -, podemos entender "Música de Feitiçaria no Brasil: conferência literária" como um texto que acolhe em si elementos dos dois grupos. Na conferência, Mário discute o desenvolvimento de determinadas manifestações populares no Brasil, à maneira dos artigos incluídos em Danças Dramáticas do Brasil. Mas, em determinadas passagens, inserem-se trechos, mais ou menos longos, da crônica "Natal, 28 de dezembro, 24 horas". Desse modo, é possível perceber no texto dois estratos marcadamente diferenciados: um estrato dissertativo, correspondente ao estudo da "música de feitiçaria" no Brasil, e um estrato narrativo, correspondente à história do ritual de catimbó. Admitindo-se, então, a existência desses dois estratos diferenciados no texto da conferência, faz-se necessário examinar de que modo eles se articulam.

A conferência começa como uma narrativa, o autor se referindo à sua viagem ao Nordeste. Mas, em seguida, o texto assume forma dissertativa, a pretexto de justificar os interesses do viajante (daqui em diante, os trechos do estrato narrativo virão em itálico, distinguindo-se dos trechos do estrato dissertativo):

\footnotetext{
"Quando andei de viagem pelo Nordeste e me dedicava em especial a conhecer a musicalidade da região, me interessei desde logo pela feitiçaria. Isso era lógico, porque feitiçaria e música sempre andaram fundidas uma na outra. Um autor esotérico apelidou mesmo a Música e a alquimia de 'filhas mais velhas da Magia', e Combarieu na sua História da Música, abandonando as provas técnicas que os cientistas nos fornecem pra explicar a criação do som, do ritmo, do instrumento, e enfim da arte musical, preferiu encontrar na magia as origens diretas da música."
}

Daí em diante, perceberemos sempre um movimento pendular entre trechos narrativos sobre o ritual de catimbó e trechos dissertativos sobre a música de feitiçaria (a do catimbó inclusive): 
"Ora eu levava pro Nordeste uma grande curiosidade pela feitiçaria musical, que no meu Estado já não existe propriamente mais. 0 povo brasileiro, de Norte a Sul, é muito supersticioso e dado a práticas feiticeiras, porém neste mundão de terras várias, as formas baixas de propiciação, louvor ou exorcismo das forças daimoníacas variam bastante (...) De S. Paulo pro Sul uma superstição mais avassaladoramente europeizada se aplica secamente às práticas do baixo espiritismo (...) Assim pois, ao chegar em Natal um dos meus cuidados foi descobrir feiticeiros de catimbó. E o acaso logo me forneceu dois, o mestre Manuel e o mestre João. No catimbó os pais de santo são chamados de mestres, que é usança tradicional portuguesa. Cândido de Figueiredo dá 'mestre' com o sentido antiquado de médico pra Portugal acrescentando apenas que em Macau e no Ceilão a palavra significa curandeiro; mas que os feiticeiros curadores se chamavam de mestres também em Portugal o prova um manuscrito de 1630 que diz 'costuma haver mulheres que debaixo do nome de mestres usavão (sic) curar os enfermos com reprovadas artes diabólicas e superstições...'".

Percebe-se que há sempre uma articulação entre os trechos narrativos e os dissertativos: esses últimos explicam ou contextualizam algum aspecto daquilo que foi exposto nos primeiros. Mas é curioso observar que, juntando os trechos referentes à experiência do pesquisador no Nordeste, que foram transcritos acima em itálico, a narrativa se desenrola perfeitamente.

No decorrer da leitura, é possível juntar os trechos relativos à história, construindo-se uma narrativa coerente, com princípio, meio e fim, passivel de leitura fora do contexto da conferência. A história se constitui, então, dentro da conferência, como um todo independente, dotado de sentido em si mesmo. Por outro lado, o estudo da música de feitiçaria no Brasil se manteria sem prejuízo de sua coerência se retirássemos da conferência os trechos narrativos. Além disso, não há uma perfeita correspondência entre os trechos narrativos e dissertativos: o estudo da música de feitiçaria excede os aspectos apresentados pela história do ritual de catimbó, assim como há trechos da história do ritual que se desenvolvem sem interrupções e não são recuperados pela argumentação do autor, fazendo sentido apenas como partes da história.

Comparando a utilização da crônica na conferência com a utilização, por exemplo, do texto da cantiga "Candombe-serê", percebe-se a diferença das funções desempenhadas por essa última e pela história do ritual de catimbó. A cantiga é trazida à conferência em meio a uma especulação sobre o significado da palavra "candombe", que poderia trazer esclarecimentos sobre a identificação entre a música negra e certos rituais da feitiçaria afro-brasileira: 


\section{EM TESE}

Belo Horizonte, v. 8, p. I-243, dez. 2004

"Lindolfo Gomes colheu em Minas o conto do bicho Pondê em que vem uma cantiga que é também exemplo dos numerosos textos bilingues existentes em nosso país. A cantiga diz assim

Me abre a porta / Candombe-serê

Minha madrinha / Candombe-serê

Que o bicho Pondê, / Candombe-serê

Quer me comer / Candombe-serê.

0 folclorista não nos esclarece no Vocabulário sobre o que seja esse refrão, e de fato o problema é difícil pois que tanto a palavra pode estar aí no sentido de dança como no sentido de magia religiosa. A forma do canto é claramente responsorial: um verso entoado pelo solista e outro verso-refrão entoado pelo coro. Ora esse processo de ladainha é utilizadíssimo pelo nosso povo tanto nas suas festas profanas como nos seus cânticos de feitiçaria."

Da cantiga, tudo o que é trazido ao texto da conferência serve à argumentação do pesquisador: a expressão cujo significado se quer apreender é pensada em sua relação com a forma do canto, e a análise desenvolvida justifica a sua apresentação no texto como documento. É impossível separar a cantiga do contexto em que está inserida, sem prejuízo da coerência do texto. Já a história do ritual de fechamento de corpo do catimbó, como vimos, corre paralela ao estudo da música de feitiçaria, sem estabelecer com ele relações de dependência. Às vezes, a história e o estudo se distanciam de tal maneira que se faz necessário promover a costura entre os dois estratos através de um artifício de enunciação: "Mas onde ficou o meu fechamento de corpo!..." exclama o narrador da história, após perder-se por mais de dez páginas discutindo os mais diversos aspectos da música de feitiçaria. É significativo o fato de que o final da conferência coincida com o final da história, em mais de duas páginas sem interrupção para explicações ou análises, sem interpretações conclusivas, demonstrando a sua autonomia no texto.

Em determinado momento de seu percurso como pesquisador da cultura popular brasileira, Mário identifica em nossas danças dramáticas (segundo ele uma das mais típicas manifestações da música popular brasileira) um modo específico de composição, que ele iria adotar em sua criação literária:

"0 que caracteriza mais 0 aspecto contemporâneo de todas as nossas danças dramáticas, é que elas, como espírito e forma, não são um todo unitário em que desenvolve-se uma idéia, um tema só. 0 tamanho delas, bem como o seu significado ideológico, independe do assunto básico. No geral o assunto dá ensejo a um episódio só, rápido, dramaticamente conciso. E esse núcleo básico é então recheiado de temas apostos a ele; romances e outras quaisquer peças tradicionais e mesmo de uso anual se grudam nele; textos e mesmo 
outros núcleos de outras danças se ajuntam a ele. Às vezes mesmo estas aposições não têm ligação nenhuma com o núcleo."

Em "Música de Feitiçaria no Brasil: conferência literária", Mário parece adotar um processo de composição semelhante àquele observado por ele em nossas danças dramáticas, ao construir sua conferência não como "um todo unitário em que desenvolve-se uma idéia, um tema só", mas como um texto heterogêneo, cujo significado transcende qualquer uma das partes.

Além da história do catimbó, a conferência de Mário incorpora outra "crônica diária" da série "0 Turista Aprendiz", uma lenda caingangue e outros materiais retirados de outros contextos, que, na conferência, mantêm-se como estratos independentes, diferentemente dos materiais nela inseridos como documentos. Assim, é possível perceber que Mário compõe sua conferência segundo princípios de composição populares, tal como fazia em suas obras literárias.

0 conceito de "tradições móveis", formulado pelo autor em um dos textos dos diários de 0 Turista Aprendiz, privilegia os processos de composição do povo frente aos elementos de que são formadas suas tradições: o povo, nos limites de sua experiência e consciência, atualiza suas tradições, acrescentando, excluindo ou modificando elementos. Também os seus textos sobre a música brasileira mostram que ele considerava que o que havia nela de verdadeiramente tradicional eram não os seus elementos, mas os seus processos de composição. 0 poeta poderia, então, trabalhar o documento folclórico, atualizando seus elementos, de acordo, no entanto, com sua condição de artista erudito.

É muito importante considerar esse ponto aqui, pois, na conferência, as duas peças centrais são da autoria de Mário. E, apesar de tematizar a cultura popular ou usar elementos da linguagem do povo, pelo menos uma delas, o estudo, é de natureza totalmente distinta da natureza das composições do povo. É o autor erudito introduzindo na tradição o dado novo. Além disso, Mário "varia" (no sentido musical do termo) o processo mesmo da composição popular das danças dramáticas, inserindo nele também o dado novo, fazendo com que as peças, em vez de se apresentarem em série, apresentem-se simultaneamente, no caso do estudo e da história do ritual do catimbó, ou dentro uma da outra, nos demais casos.

Mário lê a primeira versão da sua conferência em 1933, época em que se preocupava com a abordagem científica da cultura popular. Dar a conhecer a realidade 


\section{EMTESE}

Belo Horizonte, v. 8, p. I-243, dez. 2004

do povo brasileiro era seu interesse tanto como autor de obras literárias quanto como estudioso sistemático da matéria. Tal interesse e o reconhecimento das possibilidades oferecidas pelas duas abordagens se refletem no texto de sua conferência. Nela, essas duas perspectivas, a literária e a etnográfica, se juntam como facetas que compõem o modo de ver de um único sujeito, aquele que escreve, que vou preferir chamar de narrador do texto.

Esse narrador, em alguns momentos, se apresenta distanciado do objeto que estuda, munido de instrumentos de uma ciência importada da Europa, em outros ele se aproxima desse objeto, experienciando-o. Sente simpatia ou antipatia pelos mestres do catimbó, crê ou não crê nos espíritos que eles invocam, é tomado de embriaguez pela sua música, repete os casos contados por eles, parecendo acreditar naquilo, participar daquilo. Das diferentes posições que assume no texto, o narrador recolhe os elementos de que são formadas sua linguagem e sua visão. Desse modo, ele se nos apresenta como um representante da variedade cultural característica do brasileiro. É significativo que o narrador suspire como Macunaíma, "ai que preguiça!...", identificando-se com o nosso herói sem nenhum caráter, personagem que "deve ser entendida (...) como tentativa de avaliação exata do comportamento brasileiro, em suas oscilações."

ABSTRACT :

The present essay analyzes the articulations proposed by Mário de Andrade in his text "Música de feitiçaria no Brasil: conferência literária" between science and literature, according to the different procedures of composition identified and studied by the author in popular Brazilian cultural products.

KEY WORDS: Mário de Andrade, Brazil, folklore, literature. 